Pacific Journal of Mathematics

AN INEQUALITY INVOLVING THE LENGTH, CURVATURE,
AND TORSIONS OF A CURVE IN EUCLIDEAN $n$-SPACE 


\section{AN INEQUALITY INVOLVING THE LENGTH, CURVATURE, AND TORSIONS OF A CURVE IN EUCLIDEAN $n$-SPACE}

JOEL L. WEJNER

Let $x$ be a closed nondegenerate $C^{n}$ curve in $E^{n}$ parametrized by arc length $s$. We prove an inequality for such $x$ which lie in a ball of radius $R$. For nonplanar curves in $E^{3}$ the inequality is

$$
L \leqq R^{2} \frac{\int_{0}^{L} \kappa^{2} d s \int_{0}^{L} \tau^{2} d s-\left(\int_{0}^{L} \kappa \tau d s\right)^{2}}{\int_{0}^{L} \tau^{2} d s}
$$

where $L$ is the length of $x$, and $\kappa$ and $\tau$ are the curvature and torsion of $x$, respectively. Equality holds only if $x$ is a great circle on a sphere of radius $R$. We also obtain from the general inequality necessary conditions on the length, curvature, and torsions of $x$ in order that $x$ be a closed curve or a closed curve with at most one corner.

1. Definitions. We say a $C^{n}$ curve $x$ in $E^{n}$ is nondegenerate if it has a Frenet framing. That is, there exists an orthonormal set of vector fields $e_{1}, e_{2}, \cdots, e_{n}$ along $x$ such that

$$
\begin{aligned}
x^{\prime} & =e_{1} \\
e_{1}^{\prime} & =\kappa e_{2} \\
e_{2}^{\prime} & =-\kappa e_{1}+\tau_{1} e_{3} \\
e_{3}^{\prime} & =-\tau_{1} e_{2}+\tau_{2} e_{4} \\
\vdots & \\
e_{n}^{\prime} & =
\end{aligned}
$$

where the prime denotes differentiation with respect to arc length, $\kappa$ is the curvature, and $\tau_{1}, \tau_{2}, \cdots, \tau_{n-2}$ are the torsions of $x$. For the remainder of this paper, we assume that $x$ is nondegenerate and $\tau_{i} \neq 0$, for $i=1,2, \cdots, n-2$. In what follows we also let $\tau_{0}=\kappa$ and $\tau_{n-1}=0$.

We say $x:[0, L] \rightarrow E^{n}$ is closed if it induces a $C^{n}$ mapping $x: S^{1} \rightarrow$ $\boldsymbol{E}^{n}$, where $S^{1}$ is the circle. To say $x:[0, L] \rightarrow \boldsymbol{E}^{n}$ is closed with at most one corner means that $x(0)=x(L)$ but $x^{\prime}(0)$ need not equal $x^{\prime}(L)$.

Define $x_{i}=\left(x, e_{i}\right)$, for $i=1,2, \cdots, n$, where $($,$) denotes the inner$ product in $E^{n}$. Then from (1) we obtain 


$$
\begin{aligned}
& x_{1}^{\prime}=1 \quad+\kappa x_{2} \\
& x_{2}^{\prime}=-\kappa x_{2}+\tau_{1} x_{3} \\
& x_{3}^{\prime}=\quad-\tau_{1} x_{2} \quad+\tau_{2} x_{4} \\
& x_{n}^{\prime}=\quad-\tau_{n-2} x_{n-1} .
\end{aligned}
$$

2. The inequality. Now suppose that $x$ is closed with at most one corner; if $x$ is not closed let $x(0)=x(L)=$ origin in $E^{n}$.

THEOREM. Let $|x| \leqq R$. Then

$$
\begin{aligned}
L \leqq & R^{2}\left[\sum_{j=1}^{q}\left|\prod_{k=1}^{j-1} \mu_{k}\right|\left[\frac{\int \tau_{2 j-2}^{2} \int \tau_{2 j-1}^{2}-\left(\int \tau_{2 j-2} \tau_{2 j-1}\right)^{2}}{\int \tau_{2 j-1}^{2}}\right]^{1 / 2}\right. \\
& \left.+\left|\prod_{k=1}^{q} \mu_{k}\right|\left[\int \tau_{2 q}^{2}\right]^{1 / 2}\right]^{2},
\end{aligned}
$$

where $q=[(n-1 / 2)], \mu_{k}=\int \tau_{2 k-2} \tau_{2 k-1} / \int \tau_{2 k-1}^{2}$, and all the integrals are taken with respect to $s$ over $[0, L]$. Equality holds only if $x([0, L])$ is a circle of radius $R$ in $\boldsymbol{E}^{2}$. (Note that for $n$ odd $\tau_{2 q}=\tau_{n-1}=0$ so that the last term in the sum is 0.)

Proof. We rewrite (2) by means of integral formulas. All the integrals are taken with respect to $s$ over $[0, L]$. Since $x$ is either closed or has its "corner" at the origin, we obtain

$$
\begin{gathered}
L=-\int \kappa x_{2} \\
0=\int \tau_{i-2} x_{i-1}-\int \tau_{i-1} x_{i+1} .
\end{gathered}
$$

Here $i=2, \cdots, n$. Let $\mu_{j}, j=1, \cdots, q$ be arbitrary real numbers. Then $(3 \cdot 2 j+1)$, for $j=0,1, \cdots, q$ imply

$$
\begin{aligned}
L & =-\int \tau_{0} x_{2}+\sum_{j=1}^{q} \prod_{j=1}^{j} \mu_{k}\left[\int \tau_{2 j-1} x_{2 j}-\int \tau_{2 j} x_{2 j+2}\right] \\
& =\sum_{j=1}^{q} \prod_{k=1}^{j-1} \mu_{k}\left[\int\left(\mu_{j} \tau_{2 j-1}-\tau_{2 j-2}\right) x_{2 j}\right]+\prod_{k=1}^{q} \mu_{k} \int \tau_{2 q} x_{2 q+2} .
\end{aligned}
$$

Taking absolute values of each term in the sum and applying the Cauchy-Schwartz inequality, we obtain

$$
\begin{aligned}
L \leqq & \sum_{j=1}^{q}\left|\prod_{k=1}^{j-1} \mu_{k}\right|\left(\int\left(\mu_{j} \tau_{2 j-1}-\tau_{2 j-2}\right)^{2}\right)^{1 / 2}\left(\int x_{2 j}^{2}\right)^{1 / 2} \\
& +\left|\prod_{k=1}^{q} \mu_{k}\right|\left(\int \tau_{2 q}^{2}\right)^{1 / 2}\left(\int x_{2 q+2}^{2}\right)^{1 / 2} .
\end{aligned}
$$


But $\left|x_{2 j}\right| \leqq R$, for $j=1,2, \cdots, q+1$. Also letting

$$
\mu_{j}=\int \tau_{2 j-2} \tau_{2 j-1} / \int \tau_{2 j-1}^{2},
$$

which minimizes each of the integrals $\int\left(\mu_{j} \tau_{2 j-1}-\tau_{2 j-2}\right)^{2}$, we establish our inequality.

It is easy to check that equality holds only if $x([0, L])$ is a circle of radius $R$ in $\boldsymbol{E}^{2}$. (Remember that we demand that $\tau_{i} \neq 0, i=$ $1, \cdots, n-2$.

REMARK. The inequality in the theorem is sometimes better and sometimes worse than the inequality $L \leqq R \int \kappa$. As an example of a curve for which our inequality is better consider the curve in $E^{3}$

$$
x(t)=\left(\left(c+\frac{1}{n} \cos t\right) \cos \frac{1}{n^{2}} t,\left(c+\frac{1}{n} \cos t\right) \sin \frac{1}{n^{2}} t, \frac{1}{n} \sin t\right),
$$

where $0 \leqq t \leqq 2 \pi n^{2}, c+1 / n=1$, and $n$ is a positive integer. This is a curve that winds $n^{2}$ times around a torus of radii $c$ and $1 / n$. For this curve $R=1, L=O(n), \int \kappa=O\left(n^{2}\right)$, but

$$
\frac{\int \kappa^{2} \int \tau^{2}-\left(\int \kappa \tau\right)^{2}}{\int \tau^{2}}=O(n)
$$

as $n \rightarrow \infty$.

3. Some corollaries. By a theorem of Rutishauser and Samelson [1], we know that any closed curve in $E^{n}$ of length $L$ is contained inside a sphere of radius $L / 4$. Hence we may replace $R$ by $L / 4$ in our inequality if $x$ is closed and obtain an inequality involving only $L, \kappa$, and $\tau_{i}, i=1, \cdots, n-2$. We state the result only for closed curves in $\boldsymbol{E}^{\mathbf{s}}$.

CoRollary 1. Let $x$ be a closed curve in $E^{3}$. Then

$$
\frac{16}{L}<\frac{\int \kappa^{2} \int \tau^{2}-\left(\int \kappa \tau\right)^{2}}{\int \tau^{2}} .
$$

A similar result holds if $x$ has one corner.

CoROllary 2. Let $x$ be a closed curve in $\boldsymbol{E}^{n}$ with at most one 
corner, where $n$ is odd. It is not the case that $\tau_{2 j-2} / \tau_{2 j-1}=c_{j}, a$ constant, for $j=1, \cdots,(n-1) / 2$.

Proof. Since $|x| \leqq R$ for some $R$ we may apply the theorem. If $\tau_{2 j-2} / \tau_{2 j-1}=c_{j}$, for $j=1,2, \cdots,(n-1) / 2$, then $\int \tau_{2 j-2}^{2} \int \tau_{2 j-1}^{2}-\left(\int \tau_{2 j-2} \tau_{2 j-1}\right)^{2}=0$, for $j=1, \cdots,(n-1) / 2$. This implies for $n$ odd that $L=0$, which is an obvious contradiction.

\section{REFERENCES}

1. H. Rutishauser and H. Samelson, Sur le rayon d'une sphere dont la surface contient une courbe fermée, C. R. Acad. Sci. Paris, 227 (1948), 755-757.

Received July 11, 1977. Research supported in part by NSF Grant MCS 76-08320.

University of HaWAII at MaNoa

HONOLULU, HI 96822 


\section{PACIFIC JOURNAL OF MATHEMATICS}

\section{EDITORS}

RICHARD ARENS (Managing Editor)

University of California

Los Angeles, CA 90024

Charles W. Curtis

University of Oregon

Eugene, OR 97403

C. C. Moore

University of California

Berkeley, CA 94720

\section{J. DugundJI}

Department of Mathematics

University of Southern California

Los Angeles, CA 90007

R. FInN and J. Milgram

Stanford University

Stanford, CA 94305

\section{ASSOCIATE EDITORS}
E. F. BECKENBACH
B. H. NeumanN
F. WOLF
K. YoSHIDA

\section{SUPPORTING INSTITUTIONS}

\author{
UNIVERSITY OF BRITISH COLUMBIA \\ CALIFORNIA INSTITUTE OF TECHNOLOGY \\ UNIVERSITY OF CALIFORNIA \\ MONTANA STATE UNIVERSITY \\ UNIVERSITY OF NEVADA, RENO \\ NEW MEXICO STATE UNIVERSITY \\ OREGON STATE UNIVERSITY \\ UNIVERSITY OF OREGON
}

\author{
UNIVERSITY OF SOUTHERN CALIFORNIA \\ STANFORD UNIVERSITY \\ UNIVERSITY OF HAWAII \\ UNIVERSITY OF TOKYO \\ UNIVERSITY OF UTAH \\ WASHINGTON STATE UNIVERSITY \\ UNIVERSITY OF WASHINGTON
}

The Supporting Institutions listed above contribute to the cost of publication of this Journal, but they are not owners or publishers and have no responsibility for its content or policies.

Mathematical papers intended for publication in the Pacific Journal of Mathematics should be in typed form or offset-reproduced, (not dittoed), double spaced with large margins. Please do not use built up fractions in the text of the manuscript. However, you may use them in the displayed equations. Underline Greek letters in red, German in green, and script in blue. The first paragraph or two must be capable of being used separately as a synopsis of the entire paper. Items of the bibliography should not be cited there unless absolutely necessary, in which case they must be identified by author and journal, rather than by item number. Manuscripts, in triplicate, may be sent to any one of the editors. Please classify according to the scheme of Math. Reviews, Index to Vol. 39. All other communications should be addressed to the managing editor, or Elaine Barth, University of California, Los Angeles, California, 90024.

50 reprints to each author are provided free for each article, only if page charges have been substantially paid. Additional copies may be obtained at cost in multiples of 50 .

The Pacific Journal of Mathematics is issued monthly as of January 1966. Regular subscription rate: $\$ 72.00$ a year (6 Vols., 12 issues). Special rate: $\$ 36.00$ a year to individual members of supporting institutions.

Subscriptions, orders for numbers issued in the last three calendar years, and changes of address should be sent to Pacific Journal of Mathematics, 103 Highland Boulevard, Berkeley, California, 94708. Older back numbers obtainable from Kraus Periodicals Co., Route 100, Millwood, NY 10546.

PUBLISHED BY PACIFIC JOURNAL OF MATHEMATICS, A NON-PROFIT CORPORATION

Printed at Kokusai Bunken Insatsusha (International Academic Printing Co., Ltd.). 8-8, 3-chome, Takadanobaba, Shinjuku-ku, Tokyo 160, Japan.

Copyright (C) 1978 by Pacific Journal of Mathematics

Manufactured and first issued in Japan 


\section{Pacific Journal of Mathematics

Vol. 74, No. $2 \quad$ June, 1978

Aharon Atzmon, Spectral synthesis in some spaces of bounded continuous

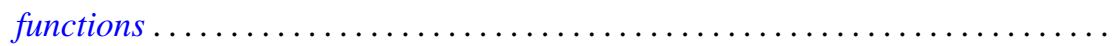

Karl Egil Aubert and Isidor Fleischer, Tensor products of ideal systems and their modules.............................................

Richard F. Basener, Several dimensional properties of the spectrum of a uniform

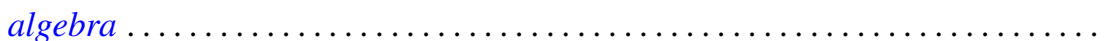

R. H. Bing and Michael Peter Starbird, Super triangulations ............. 307

Andrew Carson, Coherent polynomial rings over regular rings of finite index .....

Robert M. DeVos and Frederick W. Hartmann, Sequences of bounded summability domains .................................................

George Grätzer and R. Padmanabhan, Symmetric difference in abelian groups ....

Robert L. Griess, Jr., A remark about groups of characteristic 2-type and

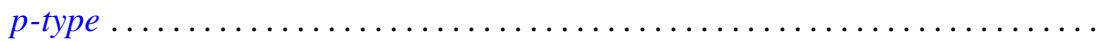

Emil Grosswald and F. J. Schnitzer, A class of modified $\zeta$ and L-functions........

Jutta Hausen and Johnny Albert Johnson, Ideals and radicals of some

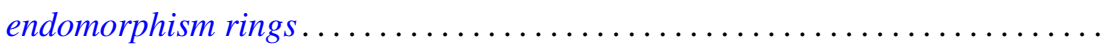

Jean Ann Larson, A solution for scattered order types of a problem of Hagendorf ............................................

Peter A. McCoy, Extremal properties of real biaxially symmetric potentials in $E^{2(\alpha+\beta+2)}$

Héctor Alfredo Merklen, Hereditary crossed product orders .

Hal G. Moore and Adil Mohamed Yaqub, Equational definability of addition in certain rings...

Robert Laurens Moore, Reductivity in $C^{*}$-algebras and essentially reductive operators. . .

Joseph Alvin Neisendorfer, Lie algebras, coalgebras and rational homotopy theory for nilpotent spaces...

William Raymond Nico, Bounded monoids

Richard Paul Osborne, Simplifying spines of 3-manifolds ...

Richard Paul Osborne, The simplest closed 3-manifolds. With an appendix by Osborne and J. Yelle.

Clayton Collier Sherman, The $K$-theory of an equicharacteristic discrete valuation ring injects into the $K$-theory of its field of quotients.... .

Mitchell Herbert Taibleson, The failure of even conjugate characterizations of $H^{1}$

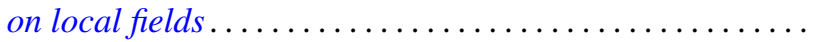

Keti Tenenblat, On characteristic hypersurfaces of submanifolds in Euclidean space ...................................

Jeffrey L. Tollefson, Involutions of Seifert fiber spaces..........

Joel Larry Weiner, An inequality involving the length, curvature, and torsions of a curve in Euclidean $n$-space .......................

Neyamat Zaheer, On generalized polars of the product of abstract homogeneous polynomials.... 